\title{
Phase 6: Review der Datenlage
}

SMPs sollten möglichst jährlich überprüft werden, jedoch immer dann, wenn ungeplante wesentliche Änderungen vorgenommen wurden. Der Betrachtungszeitraum sollte bei drei bis fünf Jahren liegen und die konkreten Entwicklungsmaßnahmen in diesem Intervall abbilden.

Eine Überarbeitung des Site-Masterplanes beeinflusst selbstverständlich die Erfolgskriterien (Kosten, Zeit, Qualität) auf Standort- und Funktionsebene. Betroffen davon sind die funktionale und strukturelle Entwicklung, Investitionsund Instandhaltungsprojekte, die Entwicklung der Standortorganisation (Struktur, Mitarbeiter, Prozesse) usw. Dies ist in die Planungsprozesse im Unternehmen $\mathrm{zu}$ integrieren und die damit verbundenen Genehmigungswege sind sowohl am Standort und als auch auf Unternehmensebene zu kommunizieren. 